\title{
Intergenerational Learning (between Generation X \& Y) in Learning Families: A Narrative Inquiry
}

\author{
Cherri Ho C.Y. \\ EdD Graduate \\ School of Professional and Continuing Education \\ University of Hong Kong \\ Tel: 852-9432-0835Ｅ-mail: suncherr@netvigator.com
}

\begin{abstract}
The purpose of this study is to examine intergenerational learning behaviour within ten Hong Kong families between Generation X parents and their Generation $\mathrm{Y}$ children. It tries to investigate intergenerational knowledge exchange, identify the characteristics of learning behaviour and culture in their 'learning families'.

A narrative inquiry approach is adopted asking participants to recall and tell stories describing their personal intergenerational learning experiences. Results indicate that $80 \%$ of the participants thought their family is a 'learning family', and intergenerational family learning is happy experience and can be bi-directional. A positive family learning culture facilitates intergenerational learning especially in the Generation $\mathrm{Y} \rightarrow \mathrm{X}$ direction. Learning methodology differs between the two generations due to societal changes and differences in their upbringing.

A conceptual framework of intergenerational family learning in relation to lifelong learning is developed. The government and public should re-define teaching and learning practise and promote intergenerational learning even in schools.
\end{abstract}

Keywords: Intergenerational learning, Learning family, Lifelong learning, Family learning culture, Generation $\mathrm{X}$, Generation Y

\section{Introduction}

We are living in a 'knowledge society' which is also referred to 'learning society' (Cribbin \& Kennedy, 2002; Jarvis, 2001; Coffield, 2000; Dearing, 1997). Besides at schools and workplace, learning also takes place in the family. A 'learning family' supports members to function better in the ever-changing world. There are relatively few publications on 'learning family' and 'intergenerational learning'.

Alexander \& Clyne (1995), recognise that families are the main context of learning. Learning within the family is lasting and influential. They use the term 'family learning' to encompass a wide range of informal and formal learning activities that involve family members in developing an understanding of, and the skills involved in, family roles, relationships and responsibilities.

Learning in the family benefits both adults and children. With mutual learning and free flow of ideas among family members, a 'learning family' is built. The National Institute of Adult Continuing Education (2003) publication indicates that family learning serves as powerful stimulus to developing a true culture of lifelong learning amongst adults and children.

To narrow the divide between the learning rich and learning poor, the government needs to promote vigorous learning within the family, to tap into the potential knowledge pool from the younger generation who are still at school and able to transfer their knowledge to their parents. Bi-directional intergenerational learning is useful facilitating communication and understanding between generations. Successful intergenerational learning fulfils age-appropriate developmental needs of youth and adults, is relational and reciprocal, drawing on the strengths and assets of each generation (Kaplan, 2001).

\section{Literature Review}

Due to the diverse application by different disciplines, it is difficult to find a consistent and precise definition for 'intergenerational learning' and 'learning family' to describe the learning behaviours taking place among family members and across generations. Intergenerational learning programs often associate with the learning for the aged.

\subsection{Generation $X$ \& Generation $Y$}

'Generation X' represents the cohort born following the post-World War II baby boom. The Online Dictionary of Social Sciences (http://bitbucket.icaap.org/dict.pl?alpha $=\mathrm{G}$ ) defines 'Generation X' as people born between 
the 1960 and 1970, at the end of the baby boom and caught in the forces of economic restructuring and globalization. This term is used in demography, social sciences and marketing industries.

'Generation $Y$ ' is the cohort born immediately after the 'Generation X', in the 1980s and early 1990s. Generation $\mathrm{Y}$ is considered as the last generation born in the 20th century. 'Generation Y' currently (as of 2006) includes those in their mid and early 20s, teenagers and children over the age of six (Savage \& Collins-Mayo, 2006; Sheahan, 2005; Sutherland \& Thompson, 2003).

The two generations learn differently and they adopt different learning methodologies and strategies. The Generation X'ers are subject to the cane, bullying and memorizing at school but the Generation Y want to dig beneath the conventional ideas and discover for themselves (West, 2005). The widespread use of personal computers, the Internet and advanced information communication technologies (ICT) plays an important role in defining the characteristics of the Generation Y population. They use the Internet as a tool for learning and socialization. They are ambitious, demanding and question everything but they are also self-absorbed, gregarious, multi-tasking, and optimistic, with a craving for those 'electronic decorations' (Hira, 2007). McLester (2007) describes them as 'Digital Native' whose learning is typically multimedia oriented and web-based and they are egocentric, with less fear of failure and they are multi-taskers. They are the first generation to use e-mail, instant messaging and cell phones since childhood and adolescence (Tyler, 2007).

Hong Kong is a capitalist city where eastern and western cultures merge. Most Generation Y in Hong Kong has grown up using computers and regard texting, messaging and blogging as second nature. They do not want to just follow instructions and they expect to learn from someone they can respect (Brushfield, 2007).

\section{2 Learning Family and Learning Culture}

Every one belongs to a family. Besides the structure, the concept of 'family' also carries cultural distinctiveness. Covey (1997) defines family culture as 'the spirit of the family -- the feeling, the 'vibes', the chemistry, the climate or atmosphere in the home' (p.20). It's the way family members relate to one another and how they feel about one another.

Each family member is interdependent of each other in the family. Covey (1997) further described 'beautiful family culture' as a 'nurturing culture where family members deeply, sincerely, and genuinely enjoy being together, where there is a sense of shared beliefs and values, where they act and interact'(p.20).

Chinese families have been handed down traditional cultures and values by their ancestors. The typical Chinese value 'xiao' (equivalent to the western term 'filial piety') is an important component of the traditional Chinese cultural framework in structuring intergenerational relationships, especially within a large extended family. The younger generations are to respect, obey and care for the older family members, while the older members are expected to provide guidance and support for the young. Among all Confucian virtues, 'filial piety' is central to the social organization of Chinese society (Kaplan et al., 2002). Chinese people emphases on the harmony in family and social relationships (Allison, 1997). Chinese families are more hierarchical in structure than western families (Ho, 1996; Shek \& Lai, 2000). Face-saving is a significant concern in solving family or social problems (Ting-Toomey, 1988). Parents are authoritative and there is a top-down relationship between parents and their children.

In regard to the Hong Kong education system, Murphy (1987) comments that the filial piety culture affects the way people learn: Hong Kong students display almost unquestioning acceptance of the knowledge of the teachers. This may be explained in terms of an extension or transfer of the Confucian ethic of filial piety. Coupled with this is an emphasis on strictness of discipline and proper behaviour, rather than an expression of opinion, independence, self-mastery, creativity and all-round personal development. (p. 43).

Intergenerational difficulties do exist as it is natural for the younger generation to reject many traditional ways of life and practices. They have different cultural experience and develop different values, fads and crazes which may not be easily accepted by their parents. There are also value changes such as internationalism, multiculturalism and consumerism among the generation Y. In Hong Kong, the family structure has shifted from the traditional extended family to a nuclear family, bringing a power and authority shift within the family.

\section{3 Lifelong Learning and Intergenerational Learning}

Dawson (2003) challenged the dominant policy discourse about lifelong learning as a tool for economic productivity and competitiveness. The dominant discourse of lifelong learning often focused on learning as acquiring skills to serve the needs of the economy but neglecting the other aspects of life and learning. Lifelong learning should be a process of 'learning to be' as first proposed in Faure et al's (1972) landmark UNESCO report. They introduce 'the idea of lifelong education as the keystone of the learning society' (p.181). However, 
many people have hijacked the discourse of lifelong education in economic terms (Coffield, 1999). Thus lifelong learning becomes more a matter of 'learning for a living' than of 'learning for living' (Martin, 2000).

A more comprehensive definition of lifelong learning is presented by the European Commission (2001) stating that all learning activities undertaken throughout life, with the aim of improving knowledge, skills and competence within a personal, civic, social and/or employment related perspective'(p. 9). Longworth \& Davies (1996) defined lifelong learning as the development of human potential through a continuously supportive process which stimulates and empowers individuals to acquire all the knowledge, values, skills and understanding they will require throughout their lifetimes and apply them with confidence, creativity and enjoyment in all roles, circumstances and environments (p.22).

Stehlik (2003) thinks that parenting is a vocation, which in itself provides a meaningful context and framework for lifelong learning. Becoming a parent is one of the most significant life events and this transition sparks a process leading to continuous learning and changes over time.

\section{The Study}

\subsection{Objectives}

The objectives of this study are to examine the intergenerational learning phenomenon within the family between parents (Generation X) and their teenage children (Generation Y). It aims to study the nature of intergenerational knowledge and experience exchange, identify the characteristics of the learning behaviour and culture within the family and explore the subject areas that parents can best learn from their children.

\subsection{Assumptions}

There are intergenerational learning (teaching and learning) events taking place within the family. Learning in the family can be bi-directional between generations. There are areas which the younger generation is more exposed and learns better, knowledge of which they can share with their parents. There are common characteristics that can be found in 'learning families' and 'intergenerational learning' is one important form of lifelong learning.

\subsection{Methodology: Narrative Inquiry}

Narrative inquiry is a tool to capture, transfer tacit knowledge and convey the rich context of knowledge and experience. Stories convey not just content but also the meaning of experience from one person to another. Research shows that knowledge is communicated most effectively through narratives. Most importantly, life stories have an inherent validity in the context if the story teller is allowed to speak in their own words (Nermien Al-Ali, 2003).

Children grow up with conversational narratives and they also tell stories around them (Kyratzis, 2005). Narrative is the driving idea behind the popular weblogs or blogs (Sumner, 2005), a technology which allows stories to be uploaded to the Internet and shared among an unlimited number of readers. The Generation $\mathrm{Y}$ is used to this type of knowledge and enjoys experience sharing. When people are offered a chance to speak freely from an integrated personal perspective, it opens the opportunity to capture a highly textured, information rich portrayal of the central issues, together with the underlying driving forces (Humpries, 2001).

For intergenerational learning, the learning contents and events are not usually written down or passed on as explicit knowledge; rather they are buried in our daily life. The events can be remembered, recalled and told as stories. Therefore requesting our participants to recall and tell their intergenerational learning stories would be an effective way to capture their experience. Stories that our participants chose to tell reflect what they think are important.

\subsection{Study Design}

Either a one-to-one face-to-face or phone interview is conducted with each individual participant. The narrative inquiry method was employed and each participant describes three incidences when intergenerational teaching and learning is taken place between the two generations. Guiding questions are given prior to the interview to ensure that the participants would cover the key concepts addressed in this study when telling their stories. They describe their learning events in detail, comment on their teaching, learning or sharing experience, and reflect on their intergenerational learning experience. After the anecdotes are told, participants' views on the concepts of 'lifelong learning', 'family learning', 'learning culture' etc, are collected. Anonymity and confidentiality are assured.

Ten pairs of parents with their child are recruited by convenience sampling. The selection criteria stipulated is that they have to be able to master English competently as they have to complete the informed consent, 
questionnaires and proof-read the transcripts of their interview content and anecdotes which are written in English though interviews are conducted in Cantonese.

\subsection{Data Management}

\subsubsection{Data Collection}

Narratives regarding intergenerational learning are collected through individual semi-structured interviews. Their perceptions and opinions on 'intergenerational learning', 'learning family' and other related concepts are obtained. The interviews are audio-taped.

\subsubsection{Data Transcription}

The voice files obtained from audio-recording are transcribed into text-based format. Data is organized according to some pre-defined attributes such as intergenerational learning, learning family, lifelong learning etc. Translation of the verbal (Cantonese) information into English is done during transcription. A copy of the individual transcript is sent to the respective participant through email for proof-reading and content accuracy.

\subsubsection{Data Processing}

All data collected is processed. It is coded to ensure confidentiality. Coded data is used to group responses to key concepts into larger and more generic typologies. They are classified, categorised and ordered for analysis. Data and information are processed manually.

\subsubsection{Data Analysis}

Theme analysis for narrative inquiry is a respected and well established method of qualitative analysis. A deductive approach of theme analysis is adopted which collects stories and sorts them by their attributes into 'etic' taxonomy. 'Etic' refers to the analysis imposed from the outside viewpoint onto the other's world, in this case done by the researcher.

\section{Results and Findings}

Parents and teenagers from 10 families are included. Altogether, twelve face-to-face interviews and nine phone interviews are conducted with 62 anecdotes collected.

\subsection{Family Structure \& Background}

Most families are nuclear families made up of parents and two teenage children. The parents are middle-aged, ranging from 45 to 52, while the teenagers are between 14 and 18 .

Most of the teenagers are studying in secondary schools while one of them in the university. Two are studying in Canada. All parents received 17 to 20 years of formal education to tertiary level while seven of them obtained Master level qualification. All are working parents.

\section{2 'Learning Family' Rating}

Participants are asked to rate their own family as to whether they think it is an ideal 'learning family' on a 10 -point scale (' 10 ' being the most ideal and ' 1 ' being the least). The score ranges from six to ten. Almost $80 \%$ of them give a score equal to or higher than seven. This is a significantly high figure which implies that participants think highly of their family as an ideal 'learning family'.

\subsection{Intergenerational Teaching and Learning Events}

There are $52(83.9 \%)$ incidences in which the teenagers play a teaching role, three (4.8\%) are incidences that the parents play the teacher role while seven $(11.7 \%)$ are cases that both the parent and the teenage child learn together. They events for learning together are studying Chinese History, learning Chinese calligraphy, playing basketball, taking photography courses, sharing academic and clinical experience and discussion on fashion.

\subsection{Matching Anecdotes}

There are eight pairs of parent and teenager reporting similar intergenerational events. Those could be events which both the parent and the teenager are similarly impressed and enjoy, thus recalled.

\subsection{Thematic Categories of Anecdotes}

Three major themes are identified.

\subsubsection{IT \& Computer Technology Related}

This constitutes $37 \%$ of all anecdotes. All the events under this category are incidences in which the teenagers play the teaching role. They include teaching their parents computer and IT skills such as transferring audio files 
to the computer, Pandora, using email and msn. Teenagers also teach their parents how to use mobile phone, digital camera and to record television programmes with a DVD recorder. They also introduce new electronic products to their parents and update their parents on IT information.

\subsubsection{Other Skills and Knowledge Areas}

This constitutes $44 \%$ of all the stories. Among them are events doing sports activities (Soccer, swimming, basketball, rock climbing), subjects learning (Mandarin, Chinese History), recreation skills (Chinese calligraphy, playing mahjong, Photography, baking), music (Karaoke, band performance, Jazz), traveling (Museum, shopping) and others such as local news, school issues, academic and clinical knowledge.

\subsubsection{Values and Attitudes}

This makes up $20 \%$ of the anecdotes, which involve religion, fashion style, sharing of life views, experience and feelings, love attitude, parenting, teaching values and principles plus western cultures sharing.

\section{Discussion and Interpretation}

\subsection{Terminology}

It is hard to comprehensively define 'intergenerational learning', 'learning family' and 'lifelong learning'. The data gathered from this study might be able to describe certain attributes and add to the knowledge regarding these terms. The discrepancy between the English and Chinese interpretation and understanding of those terms further complicates the situation. When describing those terms using different languages, one has to be aware of the semantic undertones of the language used.

Participants are reluctant to use the equivalent word of 'teaching' in Cantonese to describe the intergenerational learning phenomenon especially in the Generation $Y \rightarrow X$ direction. They prefer the equivalent word of 'sharing' instead. Apparently, the traditional Chinese 'teaching-learning' relationship implies a hierarchical relationship while 'sharing' is more on an equal ground. Even though the teenagers are more knowledgeable in certain subjects and play a teaching role, they are not comfortable with the concept that they are 'teaching' their parents.

\subsection{Contents of Intergenerational Learning in the Learning Families}

The younger generation learns from their parents about life views and experience, moral and values, manners, relationships, news and current issues or political stance. The learning is more from the Generation $\mathrm{X} \rightarrow \mathrm{Y}$ direction.

Both generations recognize that ICT and computer knowledge and skills are stronger areas among the Generation Y. More than one third of the narratives told are on this theme. Generation Y 'teaches' their parents IT skills and knowledge which they were better equipped or more exposed to. The knowledge transfer is from Generation $\mathrm{Y} \rightarrow \mathrm{X}$ direction.

The Generation $\mathrm{Y}$ also shares certain values and interests with their parents and apparently this can be bi-directional $(\mathrm{X} \leftarrow \rightarrow \mathrm{Y})$. Both generations share common interests such as music and sports which they can exchange their knowledge and learn from each other or even learn together.

\subsection{Different Learning Methodology between the Two Generations}

Both groups realize that the learning methodology and style are different between the two generations due to differences in upbringing, their background and exposure. Each generation possesses different learning characteristics and style thus they learn in different ways.

The Generation $\mathrm{X}$ is less exposed to computer technology when, thus might have difficulties using it. The generation Y has been exposed to ICT and personal computer early in life. Moreover, they are given much more exposure and learning opportunities by their parents.

The differences reflect the change in pedagogy at school and they can also be outcomes of the drastic changes in the society. The Generation X is used to learning from textbooks, memorizing book knowledge and often passive learner. They listen to their teachers and followed step-by-step instructions. They learn mainly from formal education. Contrarily, Generation Y learns by exploration through doing projects and other activities. They search for information beyond book knowledge. They also learn from their peers while self-learning is encouraged. They can easily access information through the Internet and the webs. They ask questions and challenge old practices.

Both groups find that the older generation takes longer to learn while the younger generation learns new skills faster. When learning to use new products or electronic appliances, the Generation X parents read the manuals 
and follow step-by-step instructions, while the Generation $\mathrm{Y}$ tries the products directly hands-on and play with them learning to use them. They do not read manuals but prefer to learn by trial and error.

When the teenagers try to teach their parents to use the new products or gadgets, they comment that their parents, especially their mothers, are not motivated to learn. Repeated teaching is necessary, which seems to frustrate them. They usually 'teach' their parents by hands-on demonstration with verbal explanation.

\section{4 'Intergenerational Learning' and 'Lifelong Learning'}

Learning is intrinsic and takes place at different levels: personal, family, societal, organizational, community, national and even international or global level. 'Family learning' and 'intergenerational learning' also lie on this learning spectrum. (Figure $1 \& 2$ )

Lifelong learning is learning throughout life, from cradle to grave. It is much more than the retraining of skills or continuing professional education. In this study, both groups considered lifelong learning as very important and taking place anywhere, any time.

Intergenerational learning can be bi-directional and takes place between parents and children, between siblings and cousins and even between grandparents and grandchildren. Intergenerational learning is family learning taking place across generations. Participants feel that intergenerational learning is closely related to lifelong learning.

Parents' learning attitude greatly influences the younger generation's attitude towards intergenerational family learning and lifelong learning. It is important for parents to set themselves as role models and become lifelong learners themselves. Only if parents adopt a 'willing to learn' attitude can they accept their children 'teaching' them. The participants also suggest that family learning should start early.

\subsection{Intergenerational Learning and Learning Family}

A learning family is a family in which members are willing to accept or take in knowledge from one another. Parents should develop their children early in life for independent thinking and positive lifelong learning attitudes.

A learning family demonstrates certain characteristics. Parents are expected to be open-minded, easy going and less authoritative. They should treat the teenagers as friends and maintain regular conservations with them. They act as good role models especially when they are teaching values and morals. Parents need to absorb and learn new knowledge themselves, develop wider scope of views and increase their own exposure. They are also expected to be receptive and ready to change. They have to be patient to listen to their teenage children. They should allow differences in opinions, show interest and be willing to communicate and spend time with their teenage children. Most importantly, they should believe that they can also learn from their teenage children and initiate learning by asking them questions or seeking help from them.

The characteristics of learning families are identified as followed.

\subsubsection{Who?}

When learning takes place across generations, it is intergenerational learning (between parents and children, between grandparents and parents or between grandparents and grand children). In this study, Generation $\mathrm{X}$ parents and their Generation $\mathrm{Y}$ teenage children are involved. The parents are adult learners and all participants consider themselves lifelong learners. The teenagers play an important teaching role in the intergenerational learning process with their parents, especially in the area of computer skills and technology.

\subsubsection{What? (Figure 3)}

Intergenerational learning is one form of lifelong learning involving the transfer of tacit knowledge across generations. It is informal, mostly unplanned and self-directed learning. It is situational and experiential learning through personal conversations and activities. Both the Generations X and Y contribute to intergenerational learning and each is knowledgeable and experienced in particular subjects and topics. Intergenerational learning should also take place in a bi-directional (Generation X parents $\leftarrow \rightarrow$ Generation Y teenagers) manner so that maximum benefit can be obtained.

In this complex and fast changing world, teenagers who are growing through puberty and confronted with chaos need to search for their identity, roots and reference points as anchorage to feel secure and safe. They also need a sense of belonging which can be best cultivated in their own family. Parents can provide their teenage children with their own life experience and share with them principles, values and morals which the teenagers can use as yardsticks in life. Teenagers do want some rules and regulations. They realize that they can fall back on these 
rules their parents have set for them when life becomes chaotic. Yet, family rules will have to be changed over time as children change and grow (Nolte \& Harris, 2002).

On the other hand, teenagers can contribute by teaching their parents ICT skills, new technology and trends, so as to help their parents absorb new knowledge and keep abreast with fast societal and technological changes. It is also desirable for both generations to develop common interests so they have more opportunities to learn together. There should be regular and quality conversations among family members.

\subsubsection{When?}

Participants indicates that meal times, traveling time or going on family trips, and playing games together are good opportunities for bi-directional intergenerational learning to take place. Bed time conversations and holding regular family forum are also suggested.

The National Center on Addiction and Substance Abuse (CASA, 2005) interviewed 1000 teenagers and 829 parents of teenagers, finds that frequent family dinners are associated with lower rates of teen smoking, drinking and drug use. This echoes with our findings indicating that dinner time with family members is the ideal time for intergenerational family learning.

\subsubsection{Where?}

Intergenerational learning happens anywhere, does not necessary happen in the home environment. Besides spending quality time at the dining table, going on family trips, visiting museums, watching television together in the sitting room are reported as good venues for Generations $\mathrm{X} \leftrightarrow \rightarrow \mathrm{Y}$ learning.

\subsubsection{How?}

Parents play a critical role in facilitating intergenerational learning. To foster a good learning culture in the family, participants suggest that parents should encourage curiosity and arouse children's interests to learn. They should be flexible and open-minded. Most importantly they should adjust themselves from the traditional authoritative figure.

The Generation Y participants encourage parents to ask them more questions or seek help thus allowing them opportunities to contribute their knowledge and skills. The 'asking the right questions' teaching and learning approach advocated by Socrates seems to be a workable approach for intergenerational learning.

Moreover, both generations should be able to show appreciation, enjoyment, and feel the excitement generated from new learning with their counterparts.

\section{Implications}

\subsection{Intergenerational Family Learning and Lifelong Learning Starts Early at Home}

Values and attitudes are moulded when children are very young. Parents should develop a positive family learning culture early in a child's life. A positive family learning culture fosters the development of positive and active lifelong learning attitudes and intergenerational learning both for the parents and the younger generation.

Medel-Anonuevo et al (2001) emphasise that 'if you were an active learner when you were young, you will stay that way when you are older.'(p.12). Their report also stresses that 'family environment is critical to providing a foundation for the culture of learning' (p.15). Stehlik (2003) suggests that the home in fact was a valid site for adult learning. Therefore family is the best place for learning, both for the children and the adult parents, as it provides a free and relax environment for family members to learn and there is no fear of failure.

\subsection{Teaching and Learning in Family and at School}

It is essential to re-define 'teaching' and 'learning' in this fast changing knowledge society, with the focus put on the mechanisms of learning (not teaching), one of them being intergenerational $X \leftarrow \rightarrow Y$ learning. In this study, our generation Y participants, are reluctant to use the word 'teaching' but prefer the term 'sharing' when they help their parents to learn and master new skills. The reasons could be due to the deep-rooted traditional Chinese parent-child hierarchy perception that the teenagers feel they are not in a position to 'teach' the older generation. Alternatively, Generational $Y \rightarrow X$ learning is a different teaching-learning relationship from the one they are used to experience at school in highly authoritarian classrooms (Biggs, 1996).

Frand \& Hixon (1999) see a blurring of roles and responsibilities in the emerging university environment. Very often, teaching and learning take place together with one reinforcing the other. The effect is manifested further by the widespread use of the computer technology and the Internet. The concept of 'teaching and learning' would gradually become a process of 'knowledge sharing and transfer' taking place on a more equal ground between the teacher and the learner. The Generation Y (i.e. teenagers) is far more technically competent than 
their school teachers in this area. Teenagers tend to learn what they get from television, websites and through the Internet. They dislike fake idealism and are critical of moral talks, particularly if these are preached by their teachers or their parents (West, 2005).

The results of this study shed some light in re-defining the role of the teachers at schools. The major role of school teachers now is a willingness to change students' minds, to ask enlightening questions, to build trusting relationship, to motivate students to learn, and to reinforce positive learning behaviour. Palmer (1993) thinks that 'real learning does not happen until learners are brought into relationships with the teachers, with each other, and with the subject (p.xvi)'. Giving out information and expecting students to regurgitate answers are no more a desirable pedegogy, especially when the knowledge cycles become so much shortened in this knowledge explosion era.

It's time for the authority of the Hong Kong education system to review the teacher-student relationship, the current teaching methodology and evaluation strategies. The system has to evolve in response to the changes and societal demands of a globalized knowledge economy. Friedman (2005) indicates that students have to fundamentally re-orient what they are learning and educators how they are teaching it (p.278). Our teenage participants realize that they also learn during the 'teaching' process with their parents. An intergenerational learning event is actually a reciprocity-mutual exchange process. Teaching and learning are two sides of the process coin. The 'teacher' also learns during the process. Camino (2000) suggests that what is critical to the success of a youth-adult partnership is the mutuality in teaching and learning between youths and adults. Perhaps a 'sharing' kind of learning attitude should be adopted as indicated in our intergenerational learning episodes. Intergenerational learning is a win-win, learning-learning situation while knowledge and experience is transferred and modified.

\subsection{Parenting and Family Relationship}

Most parents base their parenting practices on the way they are raised. Ijzendoorn (1992) argues that little is known about the mechanism of intergenerational transmission of parenting and that it is difficult to ascertain how people learn to parent. A traditional view on intergenerational learning asserts that parents are the principal agent of socialization in childhood, and children learn their parents' beliefs, values, and attitudes through both direct teaching and indirect observation. Therefore parents serve as good role models and have to practise what they preach.

In this new intergenerational family learning paradigm, parents' new knowledge comes from teenagers' free, willing disclosure. Generation $\mathrm{Y} \rightarrow \mathrm{X}$ learning relies heavily on the teenagers volunteering their knowledge to their parents. It is important for parents to adjust their regulatory-supervisory role so as to facilitate intergenerational family learning. Teenagers have a tendency to challenge authority, both at home and at school (Blahy, 2004). With an open mind and better understanding of the worldly changes, parents (and teachers at school) will find adult-teenager interaction becoming more complex, but also richer if parent-child relationship is well established through learning from each other.

\subsection{Importance of Generation $Y \rightarrow X$ Learning, Teenagers as Knowledge Resources}

Many governments realize that there is a growing resource demand for the ageing population. Young people can be considered as vibrant new resources especially in terms of new knowledge and family support. The future is in their hands, and the rest will be taken along on the ride. The Time Magazine chose "YOU" as the "Person of the year 2006'. People are amazed witnessing the remarkable development of the World Wide Web, and the rapid rise of various social networking websites. The Web 2.0 is a massive social experiment, innovation, creation and collaboration. The "YOU" actually implies the generation Y, as they are the major players with the information and communication technology. They would not only change the world, but would also change the way the world changed (Grossman, 2006).

Innovations and creativity are desirable attributes in the knowledge economy. Learning from the younger generation, might be a means to bring back the creativity which the adults have lost as they age. Our teenage participants demonstrate that they are willing to teach their parents what they know if parents simply ask.

\subsection{Multi-tasking}

A Dutch newspaper names the Generation Y the 'Einstein Generation', referring to their ability to perform many activities at the same time (West, 2005). This multi-tasking skill seen among the Generation Y is also reported by other authors (Hira, 2007, McLester, 2007, Tyler, 2007).

The parents of this study also realize this multi-tasking ability of their teenage children. Should they stop the teenagers from performing multi-tasks, as they were previously discouraged by their own parents when they 
were young? The traditional belief that one can succeed only if he is concentrating and focusing on one task at one time might not hold true anymore. Possibly, in the 21 st century, multi-tasking should not be discouraged but rather be seen as one of the survival skills required in the information explosion era.

\section{Recommendations and Suggestions}

\subsection{Technology and Learning}

There will be increasing intergenerational concerns in the future trend. McLester (2007) indicates that web venues become the norm for learning; even educators will be facing an overwhelming technology learning curve. A new digital divide is emerging, one that is largely generational. Masie (2006) introduces the term 'technology sandboxes', suggesting that we should play with technologies like we play in our sandboxes when we are children (p.19). The Generation X parents are to embrace technology. As seen from this study, through learning from their Generation Y children they can enjoy the games and the convenience new technology brings. Technology actually brings children closer to their parents (Tyler, 2007) with the help of mobile phones and instant messaging.

\subsection{Learning Family and Family Cultures}

Parents play a key role in creating a positive environment for intergenerational learning. Convey (1997) proposes seven habits for highly effective families. The seven habits are: be proactive; begin with the end in mind; put first things first; think 'win-win'; seek first to understand....then to be understood. These are also attributes required of a parent to upkeep intergenerational learning in the family. Convey's idea of 'interdependence, independence and dependence model' of the family is applicable to building an effective learning family.

\subsection{Empowering the Generation Y Youngsters}

Scanzoni (2000) asks adults to cultivate a fresh image of children as social agents. Adults are to view youngsters as partners in building the 'knowledge society'. She emphasizes that children should be treated as young citizens, capable of partnership with adults for social changes (p.146). If parents can alter their mental models about learning and teaching thus change the traditional authoritative parent image, they will see an unlimited knowledge resource pool right at home. Parents should recognize that their teenage children, who later become adults, will continue to serve as a valuable source of reliable information and updated knowledge for lifelong learning.

Learning from the younger generation at home is inexpensive and helps narrow the generation gaps and digital divide. Adults can establish lifelong as well as lifewide learning focuses besides limiting their learning from work or formal education. A positive attitude towards intergenerational and lifelong learning with positive family culture cultivated will induce the same in the next generation.

\subsection{Government Lifelong Education Policy}

The Hong Kong government has viewed lifelong learning in very narrow economic terms. Kennedy (2004) recognizes that there is political discourse behind the policies. Much money has been spent to retrain workers with skills that the government believes would help Hong Kong compete in the 'knowledge economy'. Rather, we should focus more on effective education, developing skills set such as knowledge, global perspective, language proficiency, innovation and creativity, which are needed to succeed in the knowledge society (Eng, 2007b). Education reforms should aim at eliminating rote learning and putting less emphasis on examinations. (Eng, 2007a). The spirit of intergenerational learning can be promoted not only at home between parents and their children, but also at schools between Generation X teachers and Generation Y students.

The government lifelong education policy has to be reviewed and encourages other lifelong learning discourses rather than just solving economic and political problems. The learning needs of parents are to be acknowledged especially on technology and computer literacy. It is important to develop a lifelong learning and education framework which expands the perspectives to include the personal and the social aspects of lifelong learning. It will be desirable that family learning and intergenerational learning can become part of the lifelong learning initiatives in Hong Kong for the entire population. Hargreaves (2000) emphasizes that in knowledge economies, people have to engage in lifelong learning for continual renewal of knowledge and skills thus we have to learn how to learn in more autonomous ways, in homes and workplaces, and not just in educational institutions.

It is also the individual's responsibility to engage in lifelong learning to continuously update his knowledge and skills. The teenagers serve as a potential knowledge source in the family for intergenerational learning and it does not require extra funding. Intergenerational learning is a very economic and effective means of lifelong 
learning. Thus the public's awareness of the importance and benefits of bi-directional intergenerational learning is to be raised.

\section{Concluding Remarks}

Although there are only few publications on the theoretical basis of 'intergenerational learning' and 'learning family', we do actually practise family learning daily to various extents without realizing it. As Collins stated in the 'Foreword' (Drucker, 2004), the important thing is to identify the 'future that has already happened' and to identify the 'changes that have already happened'. The challenge is to recognize and exploit the changes that have already occurred and see them as opportunities. Through studying the intergenerational learning phenomenon, particularly in the Generation $\mathrm{Y} \rightarrow \mathrm{X}$ direction, we may be able to exploit the vast learning opportunities among generations. Intergenerational learning helps build our intellectual as well as our cultural capital preparing us to face changes in the future. Lifelong learning implies recognizing the changes, accepting continuous change and changing with the changes.

Most participants consider their family a 'learning family'. Parent's lifelong learning attitude and attributes contributed greatly to making the family a 'learning family'. The transfer of values and morals, IT knowledge and skills using modern appliances allow the family as a whole to meet the challenges that globalization and the information age brings.

Churchman (2005) reminds us that we are facing a problem of not knowing how we are going to assess values that are out there years from now for our future generations. We cannot be sure that what we believe is right currently will still hold true in the future. To face the uncertainties and complexities that our world brings, adults should learn to learn together with the younger generation, so as to develop a dynamic value system that is responsive to the changes.

\section{References}

Alexander \& Clyne (1995). Riches beyond price: making the most of family learning. Retrieved March 6, 2004, from www.niace.org.uk/Research/Family/Default.htm.

Allison, R. E. (1997). The concept of harmony in Chuang Tzu In S. H. Liu \& R.E. Allison (Eds.). 1997. Harmony and strife: contemporary perspectives, east and west. (p.169-186). Hong Kong: The Chinese University Press.

Biggs, J. (1996). Learning, schooling and socialization: a Chinese solution to a western problem. In S. Lau (Ed.). Growing up the Chinese way, Chinese child and adolescent development (p.147-167). Hong Kong: Chinese University Press.

Blahy, T. L. (2004). Review of "Teen empower". Reclaiming Children and Youth, 13: 54-55.

Brushfield, A (2007). Generation Y redefines business practices. Retrieved Sept 30, 2007, from http://classifiedpost.scmp.com/jsarticleprint.ph.?artid=3000018.

Camino, L. (2000). Youth-adult partnership: entering new territory in community work and research. Applied Developmental Science, 4, 11-20.

Churchman, C. W. (2005).. A philosophy for complexity, from managing complexity. Retrieved Sept 23, 2005, from http://groups.haas.berkeley.edu/gem/essays/complex.html.

Coffield, E. (Ed.). (2000). Differing visions of a learning society. Bristol: Policy Press.

Coffield, F. (1999). Breaking the consensus: lifelong learning as social control. British Educational Research Journal, 25, 479-499.

Covey, S. R. (1997). The seven habits of highly effective families. U.K.: Franklin Covey Company.

Cribbin, J. \& Kennedy, P. (Eds.). (2002). Lifelong learning in action, Hong Kong practitioners' perspectives. Hong Kong: Hong Kong University Press.

Dawson, J. (2003). Lifelong learning and T.S. Eliot's Four Quartets. Studies in Continuing Education, 25, 113-124.

Dearing, R. (1997). Higher education in the learning society: summary report. London: HM Government.

Drucker, P. (2004). The daily Drucker. New York: Harper Business.

Eng, D. (2007a). Younger generation lacking key leadership skills, survey reveals. In South China Morning Post, Jun 4, 2007, Hong Kong. 
Eng, D. (2007b). Unite to safeguard talent pool, HK urged, In South China Morning Post, Jun 4, 2007, Hong Kong.

European Commission (2001). Making a European area of lifelong learning a reality. Brussels: European Commission: 678. European Commission (n.d.). Framework for Learning. Retrieved

March, 30, 2006, from http://europa.eu.int/comm/education/policies/III/life/communication/com_en.pdf.

Faure, et al. (1972). Learning to be: the world of education today and tomorrow. Paris: UNESCO.

Frand, J. \& Hixon, C. (1999). Personal knowledge management: who, what, why, when, where, how? Retrieved Dec 3, 2004, from http://www.anderson.ucla.edu/faculty/jason.frand/researcher/speeches/PKM.

Friedman, T.L. (2005). The world is flat, the globalized world in the twenty-first century. U.S.A.: Farrar, Straus and Giroux.

Grossman, L. (2006). Time's person of the year: you. In TIME Magazine, Dec 13.

Hargreaves, D. (2000). Knowledge management in the learning society In Forum of OECD Education Ministers Developing New Tools for Education Policy Making. Denmark: Copenhagen.

Hira, N. A. (2007). You raised them, now manage them. In Fortune, May 28, pp. 38-47.

Ho, D. Y. F. (1996). Filial piety and its psychological consequences. In M. H. Bond (Ed.). The handbook of Chinese psychology. (p. 155-165).. Hong Kong: Oxford University Press.

Humpries, S.E. (2001). Commentary on Denning's Narrative understanding, Reflections, 3, 54-55.

Ijzendoorn, M. H. V. (1992). Intergenerational transmission of parenting: a review of studies in nonclinical population. Developmental Review, 12, 76-99.

Jarvis, Peter (Ed.). (2001). The age of learning; education and the knowledge society. U.K.: Kogan Page.

Kaplan, M. S. (2001). School-based Intergenerational programs. Hamburg, Germany: UNESCO Institute for Education.

Kaplan, M. S., Henkin, N. Z. \& Kusano, A. T. (Eds.). (2002). Linking lifetimes: a global view of intergenerational exchange. U.S.A.: University Press of America.

Kaplan, M.S., Henkin, N.S. and Kusano, A.T. (2002). A conceptual framework for cross-cultural comparison of intergenerational initiatives. In M.S. Kaplan, N.S. Henkin, \& A.T. Kusano (Eds.).

Linking lifetimes: a global view of intergenerational exchange. (pp.1-11). U.S.A.: University Press of America..

Kennedy, P. (2004). The politics of lifelong learning in post-1997 Hong Kong. International Journal of Lifelong Education, 23, 589-624.

Kyratzis, A. (2005). Language and culture: socialization through personal story-telling practice. Human Development, 48, 146-150.

Longworth, N. and Davies, K. (1996). Lifelong learning London: Kogan Page.

Martin, I. (2000). Reconstituting the agora: toward an alternative politics of lifelong learning. In T. Sork, V. Chapman, V. and R. St. Clair. (Eds.). Proceedings of the 41st Annual Adult Education Research Conference (p. 255-260)..Vancouver: University of British Columbia.

Masie, E. (2006). Learning Trends 400. Retrieved September 10, 2006, from the Learning Consortium, www.masie.com.

McLester, S. (2007). Technology literacy and the My Space generation. Technology and Learning, 17-22.

Medel-Anonuevo, C., Ohsako, T. \& Mauch, W. (2001). Revisiting lifelong learning for the 21st Century. Germany: UNESCO Institute for Education.

Murphy, D. (1987). Office education: Hong Kong perspectives. Australian University Review, 30, 43-44.

National Center for Addiction and Substance Abuse (CASA). (2005). The importance of family dinners. Retrieved April 25, 2007 from http://www.familyfacts.org/printer.cfm?finding=8208.

National Institute of Adult Continuing Education. (2003). A NIACE Response to HM Treasury and the Department for Education and Skills consultation on the Parenting Fund,. Retrieved Dec

10, 2004, from www.niace.org.uk/organization/advocacy/DfES/ParentingFund.htm

Nermien, Al-Ali (2003). Comprehensive intellectual capital management. U.S.A.: Wiley. 
Nolte, D. L. \& Harris, R. (2002). Teenagers learn what they live (p.98-99). New York, U.S.A.: Workman Publishing Company.

Palmer, P. J. (1993). To know as we are known, a spirituality of education, U.S.A.: Harper Collins Publishers.

Savage, S.B. \& Collins-Mayo, S. (2006). Making sense of Generation Y: the world view of 15-25 years old. U.K.: Church Housing Publishing.

Scanzoni, J. (2000). Designing families, the search for self and community in the information age. U.S.A.: Pine Forge Press.

Sheahan, P. (2005). Generation Y: surviving and thriving with generation $Y$ at work. Australia: Hardie Grant Books.

Shek, D. T. L. \& Lai, M. F. (2000). Conceptions of an ideal family in Confucian thoughts: implications for individual and family counselling. Asian Journal of Counseling, 7, 85-104.

Stehlik, T. (2003). Parenting as vocation: lifelong learning can begin in the home. International Journal of Lifelong Education, 22, 367-379.

Sutherland, A. \& Thompson, B. (2003). Kidfluence: the marketer's guide to understanding and researching Generation Y-kids, tweens and teens. Canada: McGraw-Hill Ryerson.

Sumner, J. (2005). Story telling puts knowledge in context. KM Review, 8, Editorial.

Ting-Toomey, S. (1988). Intercultural conflict styles: a face-negotiation theory. In Y.Y. Kim \& W.B. Gudykunst (Eds.). Theories in intercultural communication. (p. 215-235). Beverly Hills, CA: Sage.

Tyler, K. (2007). The tethered generation. HR Magazine, May, 41-46.

West, P. (2005). A new switched-on and cynical generation. Retrieved Aug 24, 2006, from www.onlineopinion.com.au/print.asp?article=3932.

\section{Appendix}

Key: The middle section indicates intergenerational learning $X \leftarrow \rightarrow Y$ in the family

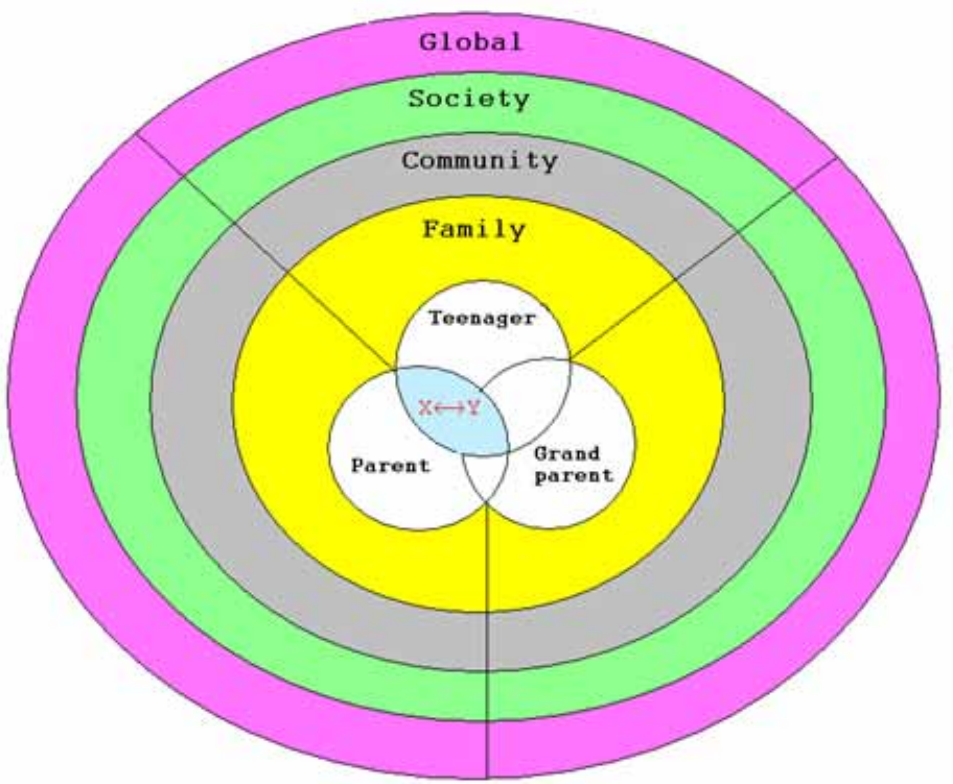

Figure 1. Intergenerational Learning and Lifelong Learning (5.4)

In the above figure, the most inner circle indicates knowledge and learning that takes place in the family, the outer circles in the community (school or workplace), at the society, and the outer most at the global world level. Individual family member of each generation learns continuously from his or her surrounding environments (family, school, community, society and global) within their respective pie section. The intersection is where Generations $\mathrm{X}$ and $\mathrm{Y}$ can share their experience and knowledge gained from various environmental levels. By doing this, maximal learning can take place across generations and experience be shared across different environments. 
The following model is designed in an attempt to put family learning into a life-wide perspective.

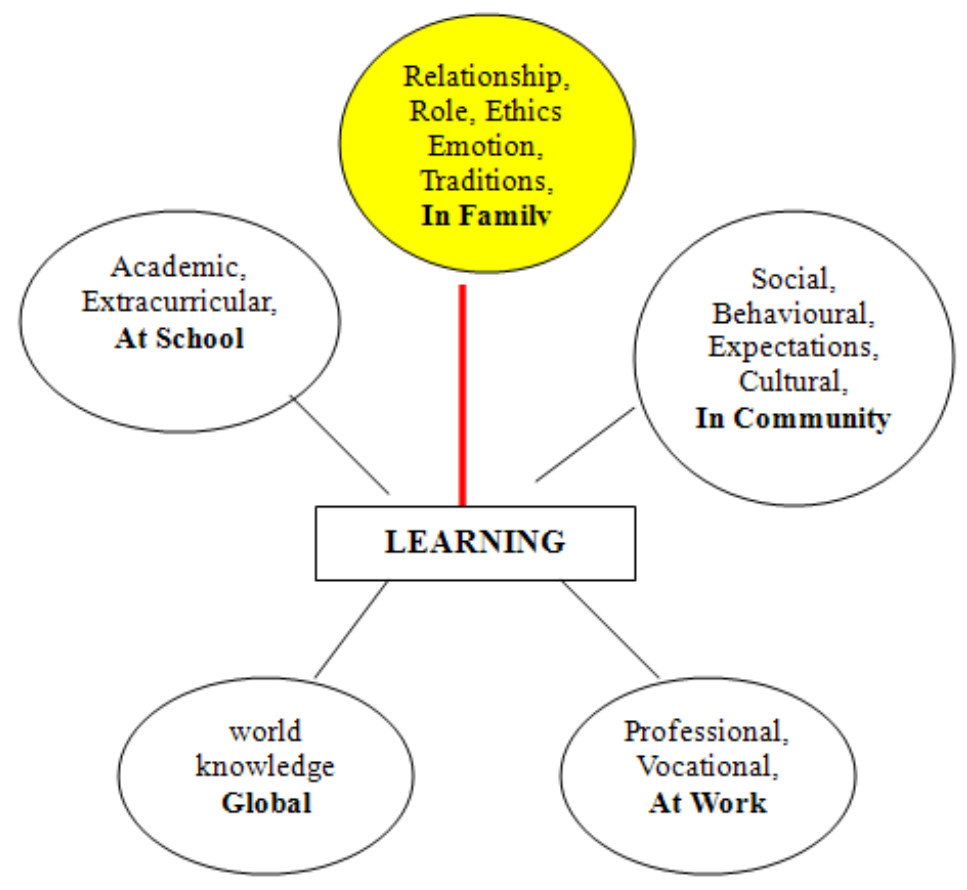

Figure 2. Family Learning and Lifewide Learning

Learning takes place at various levels under different environments. Generally, we acquire academic knowledge at school and professional experience at work. We learn social behaviour and culture in the community and gain global knowledge through various media and social interactions. Family learning is learning with family members in the most relaxed, emotionally comfortable environment. 
Key: The arrows indicate the direction of learning

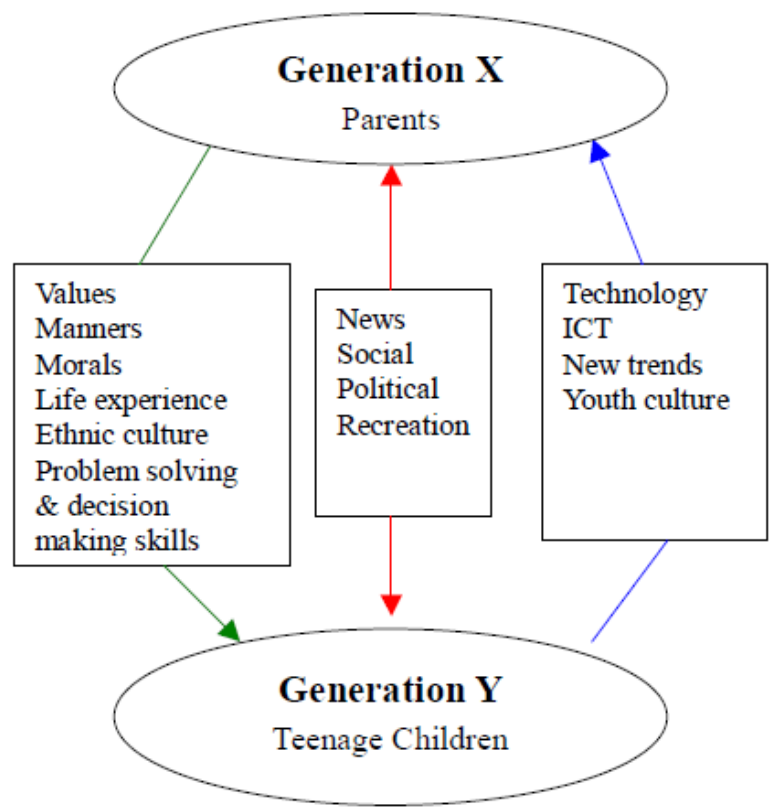

Figure 3. Subject Content for Intergenerational Learning between Generation X Parents and Generation Y Children (5.5.2)

The diagram summarizes the content of intergenerational learning. It also indicates the major direction of learning and knowledge flow between the two generations. The content in the box on the left hand side is predominantly for learning in the Generation $\mathrm{X}$ to $\mathrm{Y}$ direction (that is, for parents to learn from their teenager children). The one on the right hand side contains content for Generation $\mathrm{Y} \rightarrow \mathrm{X}$ learning (that is, parents learning from their children).

Those in the middle box involve more of mutual exchanges. The combination of the three contains important components for a happy balance learning family. 